\title{
Effects of neuromuscular electrical stimulation on muscle mass and strength in critically ill patients after cardiothoracic surgery (catastim 2)
}

\author{
A Fischer ${ }^{1 *}$, A Winkler ${ }^{1}$, M Spiegl ${ }^{1}$, A Salamon ${ }^{1}$, K Altmann ${ }^{1}$, M Themessl-Huber ${ }^{1}$, M Mouhieddine ${ }^{1}$, A Schiferer ${ }^{1}$, \\ E-M Strasser ${ }^{2}$, T Paternostro-Sluga $^{3}$, M Hiesmayr $^{1}$
}

From ESICM LIVES 2015

Berlin, Germany. 3-7 October 2015

\section{Introduction}

Intensive care unit acquired weakness (ICUAW) affects 24-77\% of patients with an ICU stay longer than one week. Neuromuscular electrical stimulation (NMES) is a feasible therapy for neuromuscular activation in sedated patients. The effect of NMES on muscle mass and strength is unclear: Randomized controlled trials (RCT) either showed no effect or beneficial effects [1]. To date, no RCT assessed the effects of NMES in a homogenous cardiothoracic surgery patient population.

\section{Objectives}

The objective was to investigate whether early NMES would be effective in preventing loss of muscle mass and strength in critically ill patients after cardiothoracic surgery.

\section{Methods}

The prospective RCT Catastim 2 included 54 patients (27 in the NMES group and 27 in the control group). In the intervention group, the anterior muscles of both thighs were electrically stimulated from the first postoperative day until ICU discharge for a maximum of 14 days. In the control group, the electrodes were applied, connected to the stimulator, but no electricity was delivered. Measurement of muscle layer thickness (MLT) of the anterior muscles of the thigh using twodimensional B-mode ultrasound was assessed every other day from postoperative day 1 to ICU discharge and at hospital discharge. Muscle strength was evaluated daily in all joints of the upper and lower extremities

${ }^{1}$ Medical University of Vienna, Vienna, Austria

Full list of author information is available at the end of the article
Table 1 Mean MRC score (271 observations).

\begin{tabular}{lll}
\hline & estimate [95\% confidence interval] & P value \\
\hline intercept & $4.07[3.79$ to 4.36$]$ & $<.001$ \\
\hline day & $0.03[0.005$ to 0.06$]$ & .02 \\
\hline NMES group & $-0.39[-0.80$ to 0.009$]$ & 0.06 \\
\hline Control group & reference &. \\
\hline day ${ }^{*}$ NMES group & $0.07[0.03$ to 0.11$]$ & $<.001$ \\
\hline day ${ }^{*}$ Control group & reference &. \\
\hline
\end{tabular}

using the Medical Research Council (MRC) scale from postoperative day 1 to ICU discharge and at hospital discharge. The effect of NMES on MLT and MRC were each analyzed in a linear mixed model.

\section{Results}

Mean MLT decreased by $0.07 \mathrm{~cm}$ [95\% CI, -0.08 to $0.05 \mathrm{~cm}$ ] per day $(P<.001)$. NMES had no significant effect on MLT $(P>.05)$.

Mean MRC score depended on the day. Moreover there was a significant interaction between NMES and day $(P<.001)$ : The more advanced the day was, the higher the mean MRC score in the NMES group was (Table 1)

\section{Conclusions}

In this RCT, NMES had no overall effect but a progressively increasing effect with the duration of NMES. This indicates that NMES helps to regain muscle strength only when applied for a sufficient number of days.

\footnotetext{
Authors' details

${ }^{1}$ Medical University of Vienna, Vienna, Austria. ${ }^{2}$ Kaiser Franz Josef Hospital, Vienna, Austria. ${ }^{3}$ Donauspital, Vienna, Austria.
}

(C) 2015 Fischer et al.; This is an Open Access article distributed under the terms of the Creative Commons Attribution License (http:// creativecommons.org/licenses/by/4.0), which permits unrestricted use, distribution, and reproduction in any medium, provided the original work is properly cited. 


\section{Reference}

1. Parry Selina $M$, et al: Electrical Muscle Stimulation in the Intensive Care SETTING. A Systematic Review*. Critical care medicine 2013, 41(10):2406-2418

doi:10.1186/2197-425X-3-S1-A818

Cite this article as: Fischer et al.: Effects of neuromuscular electrical

stimulation on muscle mass and strength in critically ill patients after cardiothoracic surgery (catastim 2). Intensive Care Medicine Experimental 2015 3(Suppl 1):A818

\section{Submit your manuscript to a SpringerOpen ${ }^{\circ}$ journal and benefit from:}

- Convenient online submission

- Rigorous peer review

- Immediate publication on acceptance

- Open access: articles freely available online

- High visibility within the field

- Retaining the copyright to your article

Submit your next manuscript at $>$ springeropen.com 